\title{
Performance of Social Media Marketing Communications of Industrial Companies
}

\author{
Natalya Izakova*, Larisa Kapustina, and Andrei Drevalev \\ Ural State University of Economics, 620144 Ekaterinburg, Russia
}

\begin{abstract}
Social media activities create additional opportunities for industrial companies to increase sales in industrial markets. The results will be influenced by the intensity of communications and posting online, as well as the content and its integrity. The article analyses current trends, prospects and possibilities of using digital marketing communications in industrial markets. Advantages and disadvantages of social media marketing for industrial companies are identified. The authors propose a methodology for assessing the performance of social media marketing for industrial companies. It includes correlation analysis, one-way ANOVA test and t-test. The authors have conducted a study of social media marketing communications of industrial companies operating in the PVC profile market. Methods of mathematical statistics were used to test the hypotheses about the influence of social media marketing activities on the results of the SEO promotion of industrial companies. Analysis of the marketing communications performance of the PVC profile producers showed that companies with active approach to social media marketing communications have significantly more search queries in the Yandex search engine.
\end{abstract}

\section{Introduction}

In the context of the pandemic, when well-established business contacts are interrupted, digital communications provide new prospects and opportunities for business in the industrial segment. Establishing online interaction with customers allows companies to increase the speed of responding to consumer requests as well as to exclude intermediaries from the customer relations. The need for digitalization of the marketing communications in industrial market is also associated with the fact that managers are often young people under 30. Online interaction is a natural and familiar form of communication for them. Currently, there are no companies or goods that are not present on the internet.

The Covid-19 pandemic has realigned companies' marketing activities. A lot of industries face the major threat of potential long-term supply chain disruptions. A decrease of purchasing power leads to a decrease in effective demand for products and services in many sectors of the economy and, in particular, industrial sectors. Exhibitions and business events which have been canceled during the pandemic, and businesses have lost one of the most efficient ways to promote goods and services in industrial markets, sign new contracts

${ }^{*}$ Corresponding author: izakovan@gmail.com 
and make investments. Marketing and sales staff have moved from offices to teleworking and switch to online interaction with customers. The new context can provide benefits to those companies that use modern methods of interaction with clients. Social media allow industrial companies to communicate with customers and influence their attitude to the brand, increase awareness of products and services, receive feedback, and boost sales $[1,2]$.

The internet, social media and other digital communication technologies have become part of the daily lives of billions of people around the world. According to the Digital 2020 report by We Are Social and Hootsuite, the number of internet users in Russia at the beginning of 2020 reached 118 million people, which is $81 \%$ of the Russian citizens. About 70 million people comprise the audience of social media, which is $48 \%$ of the total population of the country. This year has witnessed the increase of the audience attributed to seniors over 65 years old becoming new users of social media. As of January 2020, instant messengers were present on smartphones of $87 \%$ of the Russians, and $92 \%$ of mobile users have social media applications [3]. Deloitte conducted a study of media consumption in Russia in 2020. According to its results, social media are the most visited internet resources: YouTube is used by $87 \%$ of respondents, VK (Vkontakte) $-85 \%$, Instagram $59 \%$, OK (Odnoklassniki) - 55\%, and Facebook - 46\% [4].

As reported by the Articulate Marketing portal in 2019, 84\% of specialists from companies operating in the industrial market make purchase decisions after studying social media. Company executives use Facebook more often, and Facebook remains the most popular network among adults (72\% of adults use it). Facebook pages contain information about more than 50 million businesses that have their accounts. Marketing experts also point out plans to increase the use of Instagram in 2020. Instagram has been more popular for the B2C markets (72\%) than for the B2B segment (57\%) so far [5].

The internet and social media have changed consumer behavior and influenced the business practices of companies. Social and digital marketing provides significant opportunities for organizations: cutting down the costs, increasing brand awareness, and boosting sales. Communication with consumers can be established with the use of a wide range of digital channels: websites, advertising on the internet, e-mail messaging, social media, mobile applications, online publications targeting different groups of customers with different preferences regarding how they prefer to receive information. Social media tools allow companies to use direct and more intense interactive forms of communication and consumers engagement. Implementation of social media marketing (SMM) allows industrial companies to achieve their marketing goals at relatively low costs - and thus reduce marketing costs by making SMM a part of their business strategy $[6,7,8]$. In order to achieve the desired results in the most efficient way, a well-reasoned selection of social media activities is required.

The relevance of the study is attributed to the fact that marketing activities in the industrial market have particular characteristics, determined by the specific features of the market. Industrial market has limited number of customers, and they have high level of competence; the decision-making process is longer are involves many people; the decision is based on technical requirements and specific features of production. Producers and business customers tend to have closer relationship. In this regard, implementation of the SMM tools in the scope of marketing activities of an industrial company is particularly important as they focus on increasing awareness of existing and potential customers, which can stimulate interest in the company's products and encourage purchase and cooperation.

The study aims to develop and test a methodology for assessing the performance of social media activities of industrial companies, as well as to identify the SMM tools that have the greatest influence on brand awareness, reflected in the number of search queries in the Yandex search engine. 
In spite of the fact that SMM is relevant and valuable for companies operating in the industrial market, there is a lack of scientific studies focusing the implementation of social media marketing activities by industrial companies. In particular, there are only fragmentary studies on the usage of social media in the marketing activities of industrial enterprises are the researchers do not consider the results of using these tools.

There are several definitions of the "social media" concept in modern literature. Most authors define it as a set of digital platforms and technologies that allow attracting participants, interacting and exchanging information in digital form [9,10,11]. The major objective of social media marketing is to establish a dialogue with the customers, attract them and involve in interaction in the digitalized world through social media, increase traffic or attention to a brand, a product, and increase the level of awareness and knowledge about it. What is especially relevant for industrial enterprises, is that social media provide opportunity to focus on the individual customer requests, to respond to these requests in time. It is important since effective customer relationships management is a key factor defining the competitiveness of an industrial enterprise [12]. Personal relationships and interactions between the staff and customers play a fundamental role in both sales and aftersales activities, as the main elements of efficient customer relationship management in the marketing management system of an industrial company [13]. SMM allows integrating the online and offline worlds, link and unite them in order to maximize all the opportunities of digital communications.

The main advantages and possible benefits of SMM for industrial companies include the following effects: maintaining relationships with existing customers, and collecting feedback from them; sharing information with clients, which contributes to building up trust in the company; visualizing the presence in the market and marketing activities; signing up for and following the pages of industry-specific resources, professional associations; supporting the SEO promotion. At the same time, the disadvantages and possible drawbacks will include the following effects: the outcome of marketing activities is not guaranteed and can be delayed; the target audience can be difficult to reach through social media; social media marketing requires constant work: updating information, publishing news, social media posts, articles and specially created content; SMM performance and results are complex and require a set of tools of assessment.

The use of social media allows companies to establish relationships with customers by accumulating rational, emotional and social content. The limited use of these tools by industrial companies may be attributed to the fact that their products and services often have technical and utilitarian nature. In this regard, marketing managers should use social media to promote corporate brands, rather than separate product groups, be rational in communication with the audience by focusing on the functional characteristics of the products [14]. Customers who visit the social media pages of industrial companies are less active than $\mathrm{B} 2 \mathrm{C}$ clients, they are more often reluctant to comment on publications and share them in their news feed with their contacts. In order to assess the results of social media interaction of industrial companies with their customers, the analysis of SMM performance metrics can be used.

\section{Materials and Methods for Assessing the SMM Performance of Industrial Companies}

The authors propose a comprehensive methodology for assessing the performance of SMM communications of industrial companies. The methodology is based on testing hypotheses about the relationship between the indicators of a company's activities in social media and the performance of SEO promotion (Figure 1). SEO promotion allows companies to 
improve the position of their sites in search engines for certain keywords or phrases, and also attracts potential consumers.

\begin{tabular}{|c|c|c|c|}
\hline $\begin{array}{c}\text { Input } \\
\text { Indicators of social } \\
\text { media activities } \\
\text { (SMM metrics) }\end{array}$ & $\sqrt{\text { Methods }} \begin{array}{c}\text { Output } \\
\text { Correlation analysis } \\
\text { T-test } \\
\text { One-way analysis of } \\
\text { variance (ANOVA) }\end{array}$ & & $\begin{array}{c}\text { SEO promotion } \\
\text { performance }\end{array}$ \\
\cline { 2 - 4 }
\end{tabular}

Fig. 1. Methodology for assessing the SMM performance for industrial companies.

Indicators of social media activities (SMM metrics) are digital indicators that the company can measure and use to monitor the improvements due to social media activities. Different metrics are selected depending on the level of management and the specifics of the company's business. The authors propose a set of metrics for industrial companies that allow assessing dynamics in the number subscribers; feedback from users; corporate communication performance (Table 1).

Table 1. Social media marketing activity metrics for industrial enterprises

\begin{tabular}{|c|c|c|}
\hline $\begin{array}{l}\text { Type of an } \\
\text { indicator }\end{array}$ & Indicator & Characteristics of the indicator \\
\hline $\begin{array}{l}\text { Subscription } \\
\text { dynamics } \\
\text { assessment }\end{array}$ & $\begin{array}{c}\text { Followers - the total number of } \\
\text { subscribers }\end{array}$ & Content quality control \\
\hline \multirow[t]{2}{*}{$\begin{array}{l}\text { Assessment of user } \\
\text { feedback }\end{array}$} & $\begin{array}{l}\text { Likes - the number of users who } \\
\text { "liked" a publication }\end{array}$ & $\begin{array}{c}\text { Reflection of the user reaction to } \\
\text { the publication }\end{array}$ \\
\hline & $\begin{array}{l}\text { Love Rate - the share of users } \\
\text { who "liked" the publication in the } \\
\text { total number of subscribers }\end{array}$ & $\begin{array}{l}\text { Reflection of interest and } \\
\text { attractiveness of content for users }\end{array}$ \\
\hline \multirow{2}{*}{$\begin{array}{l}\text { Assessment of } \\
\text { company's } \\
\text { communication } \\
\text { performance }\end{array}$} & $\begin{array}{c}\text { Post Rate - the number of posts in } \\
\text { the page in the period under } \\
\text { review }\end{array}$ & $\begin{array}{l}\text { Assessment of the company's } \\
\text { activities in social media }\end{array}$ \\
\hline & $\begin{array}{l}\text { Content Rate - the amount of } \\
\text { content in general in the page in } \\
\text { the period under review }\end{array}$ & $\begin{array}{l}\text { Assessment of the content } \\
\text { management performance }\end{array}$ \\
\hline
\end{tabular}

The data of Yandex Wordstat can be used to assess the SEO-promotion performance. The service offers selection of keywords and shows the number of search requests for a particular product in the Yandex search engine per month, i.e. how many times people have searched for a specific phrase. The more popular the request, the higher the frequency - i.e. the number of search queries per month.

The following hypotheses were put forward in order to identify the factors influencing the SEO promotion performance:

$\mathrm{H}_{1}$. An increase in the number of subscribers leads to an increase in users' activity in the company's social media page. Set of methods used for testing: paired correlation analysis; variables for the analysis: Followers, Likes.

$\mathrm{H}_{2}$. The social media activities influence the company's SEO promotion performance. Set of methods used for testing:

- paired correlation analysis; variables for the analysis: the number of search requests in the Yandex search engine, Subscribers;

- one-way ANOVA test; variables for the analysis: the number of search requests in the Yandex search engine, Post Rate, Content Rate; 
- t-test; variables for the analysis: the company's presence in social media (social media page), the number of search requests in the Yandex search engine.

The selected methods of statistical analysis allow processing not only quantitative data, but also nominal and ordinal data, as well as varying SMM performance metrics in the scope of the analysis.

The results of the analysis reveal the role of various social media activities in increasing the brand awareness and the impact of technologies on the online promotion performance.

\section{Results and Discussion}

The methodology proposed by the authors was implemented in the approbation study of the social media activities of producers of polyvinyl chloride (PVC) moulded profile products in the Russian market. The sample includes 34 trademarks of PVC profiles. The period of the study is February 01, 2020 - September 30, 2020. The analysis focused Instagram and Facebook pages of PVC profile producers.

The data studied by the authors included the following metrics: average number of Likes of the social media posts during the period; Post Rate and Content Rate were evaluated on a three-point scale: 1 - low (1-2 posts / piece of original content per month), 2 - medium (1 post / piece of original content in 1-2 weeks), 3 - high (1 post / piece of original content in 1-3 days); the number of search requests in the Yandex search engine for the phrase: "(company name) profile" in Latin and Russian transliteration.

The results of the empirical study of social media and related digital activities of industrial companies operating in the PVC profile market are shown in Table 2.

Table 2. Results of the study of the PVC profile producers' activities in social media

\begin{tabular}{|c|c|c|c|c|c|c|}
\hline \multirow{2}{*}{ Indicator } & \multicolumn{7}{|c|}{ Business Scale } \\
\cline { 2 - 7 } & Large & Medium & Small & $\begin{array}{c}\text { Foreign } \\
\text { business }\end{array}$ & $\begin{array}{c}\text { Domestic } \\
\text { business }\end{array}$ & $\begin{array}{c}\text { Overall } \\
\text { sample }\end{array}$ \\
\hline Social media page, \% & 65 & 64 & 42 & 82 & 57 & 65 \\
\hline Followers & 5710 & 896 & 123 & 6642 & 1786 & 3838 \\
\hline Likes & 92 & 86 & 23 & 64 & 53 & 110 \\
\hline Post Rate & 3 & 2 & 1 & 3 & 1 & n/a \\
\hline Content Rate & 2 & 1 & 1 & 2 & 1 & n/a \\
\hline Photos, \% & 93 & 91 & 87 & 93 & 92 & 93 \\
\hline Posts, \% & 38 & 27 & 33 & 34 & 36 & 36 \\
\hline Shares, \% & 20 & 11 & 34 & 12 & 37 & 28 \\
\hline
\end{tabular}

The results of the study show that not all the producers have social media pages $(65 \%$ of the sample). Instagram is the most popular social media among these companies ( $47 \%$ have an official page), Facebook is the second choice (27\%). Only $18 \%$ of the companies in the sample have pages in the both social media. The number of subscribers and the frequency of publications vary significantly among the companies with both Instagram and Facebook pages. Foreign brands have the biggest number of subscribers: Deceuninck, Krauss, Schueko, Veka operate in the Russian market. At the same time, some companies with a bigger number of subscribers show low level of attractiveness. For example, the attractiveness level of the Proplex page (13.48) with 4043 subscribers is significantly lower than that of companies with a smaller number of subscribers: Montblanc (40.1), KBE (41.25), Exprof (73.2), LG Chem (141.82), Rehau (246.57).

Thirty percent of companies increased their activities in May 2020, when most people experienced self-isolation and teleworking, compared to the indicators of February. 
Most of the companies (93\%) out of those which have social media pages publish information content: photos of products and implemented projects, work process, posts about the product. The purpose of publishing this content is to gain reputation, consumer trust, become useful, show that the company has expertise and is open for interaction with customers. Only $48 \%$ of PVC profile producers publish entertaining content aimed at engaging subscribers, increasing their interest in interaction and loyalty to the company. Entertaining content includes general information about the company, congratulations on birthdays and special professional occasions. Finally, 28\% of the companies publish selling content, which mainly includes promotion and trade offers, information about discounts.

It can be noted that foreign producers operating in the Russian market are more active in social media. They have a higher average indicators of Followers and Likes.

The following conclusions were drawn from testing the hypotheses.

$\mathrm{H}_{1}$. The hypothesis about the influence of the number of subscribers on their activity on a company's page in social media was tested with paired correlation analysis carried out with the use of the Statistical Package for the Social Science software. The analysis shows no relationship between the number of subscribers and the average number of likes per post in the sample (Pearson's correlation coefficient $\mathrm{R}=0.166$ ). The conclusion indicates the need to analyse the subscribers' accounts to check if and to what extent they belong to the target audience of companies. At the same time the result may reveal possible cheating with artificially inflated number of subscribers including fake accounts.

$\mathrm{H}_{2}$. The hypothesis about the impact of activity in social media on the SEO promotion performance of an industrial company was tested in three stages.

Paired correlation analysis was carried out at the first stage. It showed no relationship between the number of subscribers and search requests dynamics in Yandex (Pearson's correlation coefficient $\mathrm{R}=0.036$ ).

One-way analysis of variance (ANOVA) was carried out at the second stage. It included the number of search requests for selected brands in Yandex as a dependent variable, and the average evaluation of Post Rate and Content Rate as a factor. The indicators of $p$-value and the $\mathrm{F}$-criterion value $(\mathrm{F}=5.955, \mathrm{p}=0.01<0.5)$ prove the statistical significance of differences in the number of search requests for selected profile brands that have different level of Post Rate and Content Rate. Those PVC profile producers which are more active on social media and publish posts 2-3 times a week, have the biggest number of search requests.

T-test was used at the third stage to test the hypothesis that there is statistically significant difference in the number of search requests in the Yandex search engine for the companies that have social media pages and those who don't have them. The values of Fcriterion (7.707) and significance indicator (0.009) allowed authors to verify the hypothesis and conclude the significance of differences in the number of search requests in the Yandex search engine between the two samples of companies. The analysis with the use of descriptive statistics showed that the number of requests for brands that have a social media page, on average, is 1191.3 , while for the brands without a social media page it is only 146.3 .

It can be concluded that social media activities of PVC profile producers including regular updates of the content and publication of new posts have significant impact on the SEO promotion performance by increasing the number of search requests in Yandex search.

\section{Conclusion}

Developing a methodology for comprehensive assessment of SMM performance for industrial companies aims to identify the social media activities that have the greatest impact on brand awareness, which is reflected in the number of search requests. 
In the scope of the study, analysis focused industrial companies - producers of polyvinyl chloride (PVC) moulded profile products in the Russian market. Advantages and disadvantages of social media marketing for industrial companies are identified, social media marketing metrics are selected, and hypotheses are formulated about the factors affecting the SEO promotion performance of industrial companies. The authors carried out assessment of SMM performance of industrial companies, including correlation analysis, one-way analysis of variance (ANOVA) and t-test. The study was carried out by the authors in 2020 including data collection. The proposed methodology allows industrial companies to assess the SMM performance on a regular basis in order to identify and analyse the dynamics of performance resulting from the use of various SMM tools.

The results of the study of the SMM activities of companies in the PVC profile market showed significant role of social media activities for industrial enterprises. Social media pages can help companies understand their customers. Alongside with that, company's publications can provide additional information about the company to customers.

Social media marketing in industrial markets requires a thorough professional approach. Creating a social media page and sharing rare publications will not create benefits. Social media marketing should involve studying the accounts of subscribers, checking that they belong to the target audience of the company, as well as creating original content relevant and useful for subscribers. Companies can find more interesting topics for interaction with customers by analysing the content of competitors with higher attractiveness from the customer's point of view.

SEO promotion performance will be improved as a result of regular, coordinated work with content, constant updates and diversification of activities. This in turn will lead to an increase in the number of requests in search engines.

The authors are planning to continue the research and study the influence of communication performance indicators on the financial results of industrial enterprises in order to obtain more complete and relevant information on the communication performance in the industrial market.

\section{References}

1. P. Kaur, A. Dhir, R. Rajala, Y. Dwivedi, Online Inf. Rev. 42(2), 205 (2018)

2. B. Lal, E. Ismagilova, Y. K. Dwivedi, S. Kwayu, Digital and social media marketing (2020)

3. Yu. Sergeeva, All the internet statistics for 2020 - numbers and trends in the world and in Russia (2020)

4. Media consumption in Russia - 2020 (2020)

5. S. Collins, 15 eye-opening B2B social media statistics (2019)

6. M. A. Shareef, B. Mukerji, Y. K. Dwivedi, N. P. Rana, R. Islam, J Retail. Consum. Serv., 46, 58 (2019)

7. W. L. Shiau, Y. K. Dwivedi, H. H. Lai, Int. J Inf. Manag., 43, 52 (2018)

8. A. S. Ajina, Entrep. Sustain. Issues, 6(3), 1512 (2019)

9. A. M. Kaplan, M. Haenlein, Bus. Horiz., 53(1), 59 (2010)

10. L. Huotari, P. Ulkuniemi, S.Saraniemi, M.Mäläskä, J Bus. Ind. Mark. 30(6), 761 (2015)

11. N. Buratti, F. Parola, G. Satta, The use of social media marketing in B2B services: A look at some "conservative" industries (2017) 
12. L. Kapustina, N. Izakova, A. Drevalev, Application of relationship marketing concept in the industrial market (2018)

13. L. Huotari, P. Ulkuniemi, S. Saraniemi, M. Mäläskä, J Bus. Ind. Mark. 30(6), 761 (2015)

14. K. Swani, G. R. Milne, B. P. Brown, A. G. Assaf, N. Donthu, Ind. Mark. Manag. 62, 77 (2017) 